\title{
Primary non-Hodgkin's lymphoma of liver with humoral hypercalcaemia
}

\author{
Cheruppolil R. Santhosh-Kumar, ${ }^{1}$ Dahish S.S. Ajarim ${ }^{1}$ and \\ Frederick D. Shipkey²*
}

Departments of ${ }^{1}$ Medicine and ${ }^{2}$ Pathology, King Khalid University Hospital, King Saud University, Riyadh, Saudi Arabia.

\begin{abstract}
Summary: A case of primary non-Hodgkin's lymphoma of the liver with associated humoral hypercalcaemia is described. The patient was successfully treated with combination chemotherapy. A similar association has not been reported previously.
\end{abstract}

\section{Introduction}

Involvement of the liver in lymphoma commonly occurs in later stages of the disease. ${ }^{1,2}$ NonHodgkin's lymphoma originating in the liver is rare. A diagnosis of primary non-Hodgkin's lymphoma of the liver (PNHLL) is seldom considered, especially in areas with high prevalence for primary hepatocellular carcinoma. ${ }^{3}$

Hypercalcaemia is an infrequent complication of non-Hodgkin's lymphoma occurring in less than $2 \%$ of cases. ${ }^{4}$ The hypercalcaemia in such cases is usually attributed to bone involvement. We report a patient with PNHLL and hypercalcaemia without evidence of bone metastasis. A similar association has not been previously reported. Previous cases of PNHLL are reviewed and possible mechanisms of hypercalcaemia are discussed.

\section{Case report}

A 37 year old Yemeni male was referred for further investigation of possible liver metastasis from an unknown primary tumour. The patient gave a history of right upper abdominal swelling and pain for 4 months and progressive non-obstructive jaundice and vomiting for 2 months. He had lost $20 \mathrm{~kg}$ in weight and had night sweats without fever. There was no past history of jaundice or alcohol intake. Physical examination showed a cachectic, jaundiced man with no peripheral lymphadenopathy or stigmata of chronic liver disease. A tender

Correspondence: C.R. Santhosh-Kumar, M.R.C.P. Division of Medical Oncology, University of Colorado Cancer Center, Denver, Colorado 80262, USA.

* Present address: Department of Pathology, University of Mississippi Medical Center, Jackson, Mississippi, USA.

Accepted: 29 January 1990 diffusely enlarged liver was palpable to $5 \mathrm{~cm}$ below the right costal margin with a span of $20 \mathrm{~cm}$. There was no splenomegaly. Systemic examination was otherwise normal.

Laboratory analysis showed persistent hypercalcaemia (range 3.25 to $3.92 \mathrm{mmol} / 1$, corrected for albumin), with normal serum phosphate and low chloride (range 94-99 mmol/l). Blood urea and creatinine were normal. Serum immunoreactive parathyroid hormone (PTH) was $9 \mathrm{pmol} / 1$ (normal 44-68) (radioimmunoassay sensitive to mid-region of parathyroid hormone, Bioscientia Laboratories, Mainz, West Germany), with serum calcium in normal range and 1-alpha, 25-dihydroxy vitamin $D_{3}$ was normal at $31 \mu \mathrm{g} / 1$ (normal 20-100). Serum bilirubin was $71 \mu \mathrm{mol} / 1$, alanine transaminase $77 \mathrm{U} / 1$, aspartate transaminase $94 \mathrm{U} / 1$, gamma GT $431 \mathrm{U} / \mathrm{l}$, alkaline phosphatase $1518 \mathrm{U} / \mathrm{l}$ and lactate dehydrogenase $1032 \mathrm{U} / \mathrm{l}$. Total serum protein was $71 \mathrm{~g} / 1$ with albumin of $28 \mathrm{~g}$. Serum immunoelectrophoresis showed polyclonal increase in gamma globulins. Haemogram was normal. Serum ferritin was elevated at $537 \mu \mathrm{g} / \mathrm{ml}$. Prothrombin time was normal. Hepatitis B (HB) surface antigen was negative but anti-HBc and anti-HBS were weakly reactive. Antibodies to human T cell leukaemia virus (HTLV-III) were absent in serum.

Computed tomographic (CT) scans (Figure 1) of the abdomen performed a week prior to admission showed multiple, discrete, rounded lesions in both lobes of the liver. There was no evidence of splenomegaly or lymph node enlargement. Chest $\mathrm{X}$-ray, barium enema and upper gastrointestinal endoscopy were normal. Bone marrow aspirates and biopsies from both iliac crests did not show any abnormality. Skeletal radiology showed generalized decrease in bone density with no focal lesions. ${ }^{99 \mathrm{~m}} \mathrm{Tc}$ isotope bone scan showed generalized increased uptake without any focal lesions. 


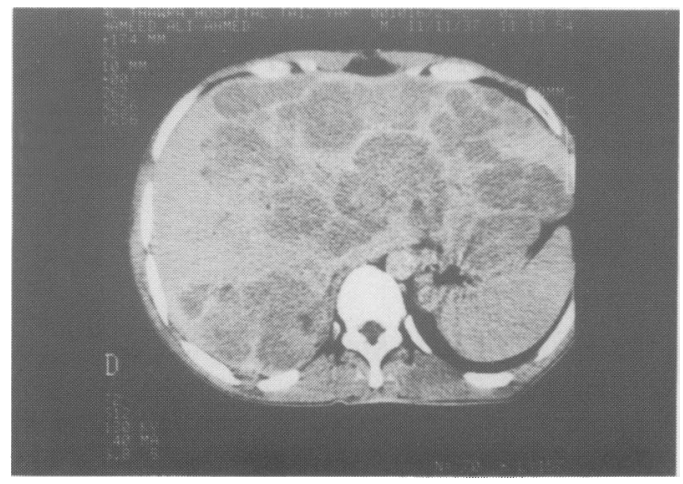

Figure 1 CT scan of abdomen showing multiple areas of low attenuation in both lobes of the liver.

Liver biopsy showed complete replacement by large lymphoid cells with cleaved nuclei, prominent central nucleoli and numerous mitotic figures (Figure 2). Stains for HBSAg, alpha fetoprotein and epithelial membrane antigen were negative. $A$ diagnosis of primary diffuse large cell nonHodgkin's lymphoma ${ }^{5,6}$ limited to the liver was established.

Chemotherapy was instituted with a combination of methotrexate, doxorubicin, cyclophosphamide, vincristine, bleomycin and prednisone (MACOP-B). ${ }^{7}$ Serum calcium returned to normal on the fourth day of chemotherapy and remained normal at the time of last assessment.

Ultrasound and CT scans of the abdomen on completion of MACOP-B treatment, at 15 weeks, showed substantial resolution of the liver lesions except for two areas of low attenuation. Ultrasound guided liver biopsy of the areas did not show any evidence of lymphoma. Subsequently he was given two cycles of chemotherapy with ifosfamide and etoposide over a period of 6 weeks. CT scans of the liver continued to show two small lesions and a repeat liver biopsy did not show any evidence of lymphoma. No further treatment was given. A repeat isotope bone scan was normal. The patient remains in continuing complete remission at last assessment, 24 months after diagnosis.

\section{Discussion}

The diagnosis of PNHLL in our patient is based on histological diagnosis of lymphoma in liver with primary symptoms of liver disease, absence of lymphadenopathy, splenomegaly or other organ involvement and normal bone marrow examination and blood counts. ${ }^{6}$ The hypercalcaemia in our patient was related to the lymphoma since there was no history of vitamin or mineral intake, prolonged immobilization, signs of renal, bone or

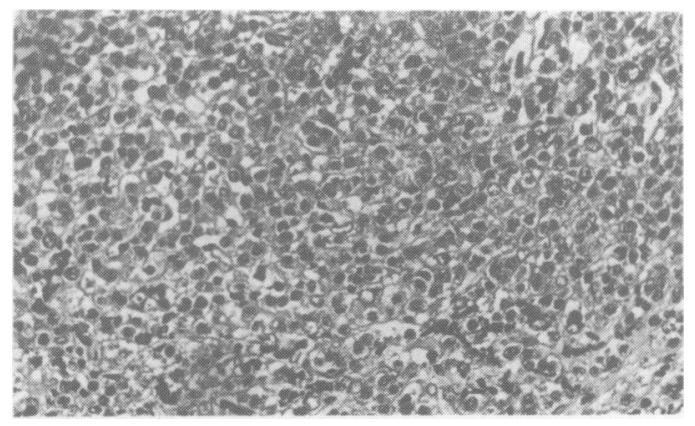

Figure 2 Liver biopsy showing large lymphoid cells with prominent nucleoli $(\mathrm{H} \& \mathrm{E} \times 172)$.

endocrine disease or sarcoidosis. We believe that the pathogenesis of hypercalcaemia is humoral as skeletal radiology and isotope scans showed a picture of generalized bone resorption without focal metastatic deposits. Associated primary hyperparathyroidism as a cause of osteoclastic bone resorption was excluded because of reduced PTH and vitamin $D_{3}$ levels.

Primary hepatic lymphoma has been reported in 31 patients, of which 8 were autopsy diagnoses. ${ }^{3,8,7}$ Twenty one patients were males. Clinical presenta tion was generally non-specific with abdomina pain and weight loss being the predominant symp toms. The liver lesions were in the form of single nodules in 15 patients and multiple in 16. The lymphomas were of diffuse large cell type in the majority of cases. Of the 23 patients diagnosed in life, 7 were treated with surgery and or chemotherapy and 12 with chemotherapy alone. The median survival of these patients was 1.8 years with a range of 0 to 10 years.

Hypercalcaemia was not associated with any of the previously reported cases of PNHLL. Hypercalcaemia has been described in non-Hodgkin's lymphoma and Hodgkin's disease rarely in the absence of bone involvement, where humoral mediators like vitamin $\mathrm{D}_{3}$ and PTH-like substances have been implicated..$^{10,11}$ Other agents like epidermal growth factor, platelet derived growth factor, tumour necrosis factor, osteoclast activating factor and prostaglandins have been suggested as humoral mediators of hypercalcaemia in the past. ${ }^{10}$ Recently, several investigators have isolated a PTH-like protein thought to be responsible for humoral hypercalcaemia of malignancy, mainly in patients with solid tumours. ${ }^{12}$ This protein has structural and functional similarities to human PTH and recently a radioimmunoassay has been developed for quantitative analysis. ${ }^{13}$

In summary we report the first case of PNHLL associated with humoral hypercalcaemia of malignancy which was successfully treated with 
chemotherapy. A diagnosis of lymphoma should be considered while investigating a patient with suspected liver metastasis as this may be a potentially curable condition.

\section{References}

1. Edmonson, M. \& Peters, R. Neoplasms of the liver. In: Schiff, E. (ed.) Diseases of the Liver. J.B. Lippincott, New York, 1982, pp. 1101-1158.

2. Rosenberg, S.A., Diamond, H.D., Jaslowitz, B. \& Craver, L.F. Lymphosarcoma: a review of 1269 cases. Medicine (Baltimore). 1961, 40: 31-84.

3. Osborne, B.M., Butler, J.J. \& Guarda, L.A. Primary lymphoma of the liver, ten cases and a review of the literature. Cancer 1985, 56: 2902-2910.

4. Canellos, G.P. Hypercalcemia in malignant lymphoma and leukemia. Ann NY Acad Sci 1974, 230: 240-246.

5. National Cancer Institute sponsored study of non-Hodgkin's lymphomas: summary and description of a working formulation for clinical usage. The Non-Hodgkin's Lymphoma Pathologic Classification Project. Cancer 1982, 49: 2112-2135.

6. Caccamo, D., Pervez, N.K. \& Marchevsky, A. Primary lymphoma of the liver in the acquired immunodeficiency syndrome. Arch Path Lab Med 1986, 110: 553-555.

7. Klimo, P. \& Connors, J.M., MACOP-B chemotherapy for the treatment of diffuse large-cell lymphoma. Ann Intern Med 1985, 102: 596-602.

\section{Acknowledgements}

We thank Professor B. Ayoola, Gastroenterology Division, for review of the manuscript and Mr K.C. Kyriacou for help with photography.

8. Daniel, S.J., Attiyeh, F.F., Dire, J.J., Pyun, H.J., Carrol, D.S \& Attia, A. Primary lymphoma of the liver treated with extended left hepatic lobectomy. Cancer 1985, 55: 206-209.

9. Redondo, C., Martin, L., Cano, A.L., Cabellon, P., Vazquez. J.M. \& Collantes, J. Primary lymphoma of the liver treated with hepatic lobectomy and chemotherapy. Cancer 1987, 60: 736-740.

10. Rieke, J.W., Donaldson, S.S. \& Horning, S.J., Hypercalcemia and vitamin D metabolism in Hodgkin's disease. Is there an underlying immunoregulatory relationship? Cancer 1989, 63: 1700-1707.

11. Breslau, N.A., McGuire, J.L., Zerwekh, J.E., Frenkel, E.P. \& Pak, C.Y.C. Hypercalcemia associated with increased serum Calcitriol levels in three patients with lymphoma. Ann Intern Med 1984, 100: 1-7.

12. Editorial. Humoral hypercalcemia of malignancy. Ann Intern Med 1988, 108: 454-457.

13. Budayr, A.A., Nissenson, R.A., Klein, R.F. et al. Increased serum levels of a parathyroid hormone like protein in malignancy associated hypercalcemia. Ann Intern Med 1989, 111: 807-812. 